\title{
Brian Garfield: la violencia como única solución
}

\section{Brian Garfield: violence as the only solution}

\author{
ENRIC MAS AIXALÀ \\ Universitat Politècnica de Catalunya \\ enricmas@gmail.com \\ ORCID ID: 0000-0002-1552-7775
}

\begin{abstract}
Resumen: Analizamos el impacto de Death Wish (1972) de Brian Garfield y cómo sus adaptaciones cinematográficas la convirtieron en una obra de culto. Nos preguntamos por el fondo de la cuestión y otros aspectos que se han quedado al margen en los escasos trabajos académicos realizados hasta la fecha, con especial atención a la trascendencia moral y social de su legado.
\end{abstract}

Palabras clave: Brian Garfield, Death Wish, Michael Winner, Charles Bronson, violencia, justicia, hardboiled, roman noir, Heart of Darkness, Apocalypse Now.

\begin{abstract}
We analyze the impact of Brian Garfield's Death Wish (1972) and how his film adaptations turned it into a work of worship. We ask about the substance of the matter and other aspects that have been left out of the few academic works carried out to date, with special attention to the moral and social significance of his legacy.
\end{abstract}

Key Words: Brian Garfield, Death Wish, Michael Winner, Charles Bronson, violence, justice, hardboiled, roman noir, Heart of Darkness, Apocalypse Now. 


\section{Cuestiones taxonómicas}

¿Qué es lo que hace que, todavía hoy, muchos no hayan digerido su impacto? ¿Qué puede significar una obra para que muchos eviten hablar de ella y para que aquellos que lo hacen no vayan al fondo de lo que plantea?

Quizás, ahora que hace poco que Brian Garfield nos ha dejado (diciembre de 2018) y se ha cumplido el cuadragésimoquinto aniversario del estreno de la película basada en su obra (Death Wish, 1974), sería interesante ir al fondo del asunto. En un intento de clasificarlo todo, siempre tendemos a la simplificación y al error. Y esto es lo que ha sucedido desde que se publicó la novela Death Wish (1972) y, más todavía, desde que la película, protagonizada por Charles Bronson y dirigida por Michael Winner, tuvo un ruidoso impacto.

Brian Garfield creó algo que quizás no era nuevo, que quizás no significó una revolución literaria o cinematográfica, que quizás no parecía un arma de cambio social o de comprensión..., o quizás sí. Las claves las encontramos ya al intentar comprender qué hay de nuevo en esta obra o qué hay de descubrimiento, aunque me inclino a pensar que Death Wish es más un descubridor en sí mismo.

Death Wish no es una obra del género hardboiled, o roman noir, término francés que pasó de describir la novela gótica británica (littérature noire) a designar la novela negra. El término films noirs, acuñado en 1946 por los críticos franceses de cine Nino Frank y Jean-Pierre Chartier (Flory, 2008: 18), fue trasladado al inglés por Charles Higham y Joel Greenbert (Hollywood in the Forties, 1968), y pasó de ser utilizado por los estudiosos para referirse a los american noir films de 1941 a 1958 a utilizarse para definir prácticamente toda la literatura/cine que se le pareciese (Flory, 2008: 18), aunque fuera remotamente. Finalmente, por culpa de las constantes controversias sobre qué películas lo eran y cuáles no, y de los graves problemas internos incluso a la hora de establecer una definición, el término se dejó de lado (Flory, 2008: 19).

La cosa ya no pintaba demasiado bien cuando tuvieron que ser los franceses los que salvaran el reconocimiento de los norteamericanos de su propia literatura, tal como explica el propio Barry Gifford, fundador de la editorial Black Lizard Books, especializada en reediciones de novelas del estilo de novela negra. Gifford, en un viaje a París (1983), vio en una librería un montón de obras de Jim Thompson y de David Goodis y recordó que las leía cuando tenía doce años. Compró un buen puñado de estos libros (en francés) y se dio cuenta de que no existían ediciones en inglés en EE. UU.: era necesario redescubrirlos (Mandeville-Gamble, 1997: 2). Así despegó su editorial. Aunque -recordemos-en nuestro país, las fabulosas Seleccions de la Cua de Palla (Edicions 62), colección dirigida por el escritor Manuel de Pedrolo, se adelantaron, en una fecha tan 
temprana como 1981, a hacer en catalán lo que Barry Gifford haría en inglés.

Muchos críticos e investigadores nos perdemos en definiciones: intentos de poner un marco a la creación cuando ya la clasificación en sí la encajona. Aquí tenemos una de las claves de Death Wish: no es una novela western ni tampoco encaja en las historias de detectives (no hay ningún William Crane, ningún Paul Pine, ningún Marlowe); tampoco es una historia de detectives aventureros o mercenarios (como el Travis McGee de John D. MacDonald), ni una historia de gánsteres (This is DynamiteCorruption City, 1951); no relata la vida de los bajos fondos y del hampa (como sí lo hace de forma magistral George V. Higgins, tan injustamente olvidado, en sus excelentes The Friends of Eddie Coyle, de 1972, y The Digger's Game, de 1973); no es ningún melodrama con pinceladas biográficas de gente que se ve inmersa en la búsqueda del sueño americano (Serenade, 1937, de James M. Cain; o la que probablemente es la mejor plasmación del funcionamiento de la industria Hollywood-cloaca - iya en 1938!--, de Horace McCoy, I Should Have Stayed Home); tampoco encaja en las narraciones de policías jugando al gato y al ratón con asesinos (también en serie), ni en las de familiares de víctimas que hacen de perseguidores ( $A$ Kiss Before Dying, 1953); tampoco es una historia de superhéroes...

Solo en el intento de definir la narración de Death Wish ya encontramos una de sus claves. Brian Garfield hizo algo que, según podemos constatar, no se había hecho antes (al menos, no con tanta profundidad), al crear, con toda probabilidad, un género en sí mismo. Por ejemplo, reunió la esencia del western y tuvo la osadía de implantarla en la Manhattan de los años 70 (¿cómo se puede disparar indiscriminadamente en las calles de este distrito neoyorquino y hacer que no suene falso?). Por ejemplo, el protagonista no es un muerto de hambre ni proviene de ningún suburbio social: es culto, tiene suficiente dinero como para que lo consideremos de clase media, no tiene problemas familiares, carece de traumas infantiles o enfermedades psicológicas... Podríamos pensar en venganza..., pero no, tampoco se trata de eso: no es una venganza personal, presente en todos los subgéneros imaginables. Y estos son solo algunos ejemplos.

\section{Aspectos distintivos de Death Wish}

La clave que ha hecho gastar tanta tinta (y kilómetros de celuloide) reside en el hecho de que Garfield profundizó en la psicología del sufrimiento humano hasta límites, de tan llanos, insoportables. Sufrimiento de alguien a quien matan a su mujer y violan a su hija simultáneamente (quien queda tan psicológicamente afectada que evoluciona hasta la catatonía) y que se va derrumbando página a página, sin provocar ninguna reacción realmente violenta hasta la página 106 (de una 
edición de 142) (Garfield, 1991). Estos aspectos provocan que, el lector que haya sufrido algún incidente doméstico, de pareja, familiar, que le haya creado hipersensibilidad, con toda probabilidad apartará la vista del libro docenas de veces, para volver a ponerla las mismas veces... más una: la que le hará continuar leyendo. Nada de violencia desde la primera página, nada de tramas a ritmo de videoclip, nada que no sea dolor, real, casi cotidiano, y cada vez más interior.

En la primera línea ya se ha producido la salvaje agresión: «Más adelante intentó recordar dónde estaba en el momento que atacaban a Esther y a Carol» (Garfield, 1991: 5). Y avanza con conversaciones, aparentemente inocentes, sobre los políticos y el urbanismo: «Los políticos se quejan del vandalismo y ellos mientras tanto van demoliendo monumentos históricos para hacer sitio a estas hueveras» (Garfield, 1991: 5); la incomunicación: «El sistema telefónico ya no funciona, el correo no sirve» (Garfield, 1991: 6); la ya tan actual visión del sistema (neo)capitalista sobre el individuo: «Hoy en día, no somos nada más que series de siete dígitos» (Garfield, 1991: 10); una descripción detallada de las artimañas legales que utilizan impunemente los ricos para no pagar impuestos: «Bueno, evidentemente hay las tácticas típicas» (Garfield, 1991: 13); el desastre del sistema policial y judicial: «A veces los atrapamos» (Garfield, 1991: 18); la no prevención del delito por ningún medio... El sistema se cae a trozos en paralelo con el estado anímico de Paul Benjamin.

Y, ¿después? Después «los hombres deberían ser capaces de conservar algunas ilusiones» (Garfield, 1991: 70), y, aunque «no quiero solucionar nada. Quiero proteger a mi familia» (Garfield, 1991: 81), «es demasiado tarde para mejorar las cosas» (Garfield, 1991: 80)... O no.

Otro misterioso aspecto que nos ofrece de forma contundente Death Wish es la trascendencia moral, social y legal del caso. Los vigilantes (vigilantism) son tan antiguos como la humanidad, con casos similares al de Paul Benjamin, pero no han recibido ningún apoyo político ni institucional porque moralmente son demasiado poderosos. ¿Por qué? Porque la posibilidad de que tengan razón (aunque sea en parte) es muy peligrosa, y la manera de no reconocerlo es criticándolo y silenciándolo, sin diálogo posible. Una fórmula aplicada en los estándares políticos: si no deseas que el pueblo decida sobre algo, no le des la oportunidad directa de decidir, porque, ¿qué pasa si la decisión del pueblo no gusta a los poderes? Se nota que Brian Garfield caló hasta los tuétanos.

\section{CONTEXTO DE PRODUCCIÓN Y RECEPCIÓN}

La adaptación cinematográfica llegó en 1974 de la mano del dúo Michael Winner-Charles Bronson, después de que el director Sidney Lumet abandonara el proyecto en el que el actor Jack Lemmon hubiera 


\section{Brian Garfield: la violencia como única solución}

protagonizado la película (Tranter, 2008: s. pág.). La fuerza del proyecto ya daba miedo: Garfield se inspiró en unos incidentes de vandalismo que sufrieron él y su mujer y, después de pensar «mataré al hijo de puta», escribió la novela... en dos semanas (Tranter, 2008: s. pág.). Este hecho, como ya hemos visto, impregna la historia. El agente de Charles Bronson, Paul Kohner, intuyó que se trataba de una película «peligrosa» y Bronson le contestó que pensaba «que el mensaje era el mismo» al que recurrían muchas de sus películas (Davidson, 1974: 7d). Pero fue el propio Winner quien acabó persuadiendo a un Bronson nada convencido para el papel de un contable diciéndole que podían cambiar su parte por «la de un arquitecto más activo y viril», y que todos ganarían «mucho dinero» (Davidson, 1974: 7d).

Este es uno de los escasos ejemplos en el mundo del cine en los que, por pura casualidad (dinero), la película se agarra a las entrañas de la novela. Lo que ni tan siquiera el autor supo ver (llegando a renegar, posteriormente, del resultado) fue lo que consiguió un equipo con ganas de hacer algo para llenar cines. Simplificaron el retrato psicológico (con algunos aciertos, como cuando a Paul le llegan las fotos reveladas de su mujer, ya muerta) y añadieron violencia, sí, pero involucrando a todo el sistema policial y judicial estadounidense. Lo que la novela enseña, a través de una cortina traslúcida, solo al final, y que denota la complicidad de la policía con lo que hace el vigilante, en la película acribilla al espectador y a su posición ante la justicia. «¿Cómo llamas a la gente que, ante una situación de peligro, no hace nada? Nada más que esconderse», pregunta Paul a su yerno, quien le contesta «civilizada», y acto seguido Paul hace un gesto de desaprobación (D’Ambrosio, 2011: 156). Esta conversación define la base del sistema socioeconómico dominado por una élite: que la gente civilizada no haga nada aunque crea que la situación no es justa o que es mejorable, muy en la línea de lo que reprocha la famosa cita atribuida a Edmund Burke (aunque no existe ninguna fuente acreditada que establezca su autoría): «para que triunfe el mal, basta con que los hombres buenos no hagan nada», la cual, en realidad, podría derivar de la cita de John Stuart Mill: «los hombres malos no necesitan nada más, para conseguir sus fines, que hombres buenos que miren y no hagan nada» (Mill, 1867: 36). Y, en el caso de que alguien quiera hacer algo, hay que ponerle obstáculos de todo tipo, desde burocráticos hasta morales, con ruegos de confianza en el sistema.

Lo que sucedió ya es historia. Un éxito masivo, con colas en los cines. Los de Paramount, que en un principio no querían hacer nada con Death Wish, en el estreno ya tenían tanta confianza en la película que ordenaron aumentar el precio de la entrada de 3,50 a 4,00 dólares, cuando la media en los EE. UU. era de 1,88 dólares y únicamente se habían pagado estas cifras en dos superproducciones del momento, The Godfather (1972) y The 
Great Gatsby (1974) (Talbot, 2006: 18). El impacto al ver la película es recordado por Todd Roberts, hijo del productor: «Tenía mucho que asimilar. No estoy diciendo que tuviera pesadillas, pero estaba alterado» (Talbot, 2006: 18). El propio Winner estaba inmensamente sorprendido por el éxito de la película: «He hecho películas con Charlie con mucha acción $[\ldots]$. Death Wish no era espectacular [...]. No había sangre, no había nadie luchando» (Talbot, 2006: 20). Y Garfield, muy descontento con el resultado, inició un intercambio de misivas con Winner, de las que destaca la famosa respuesta a Garfield «iEs un idiota!», y también: «[Garfield] ha dicho, "Oh, han hecho esta terrible película sanguinaria". Bueno, ¿qué pensaba él que había escrito? ¿Blancanieves?» (Talbot, 2006: 20).

Garfield estaba más que preocupado con el estreno televisivo de Death Wish en los EE. UU. (de costa a costa) el 10 de noviembre de 1976, y es entonces cuando nos muestra la clave de su impacto al afirmar: «Pienso que es una película peligrosa $[\ldots]$ y la prueba es que diversas personas ya han cometido crímenes de vigilante inspirados por la película» (D’Ambrosio, 2011: 260). Incluso sugirió a los directivos de la CBS que no la emitiesen (D'Ambrosio, 2011: 260). Este es, con toda probabilidad, el fondo del asunto. No las críticas del autor a las escenas de violencia, al tratamiento de la escena de la violación o al cambio del final respecto a su libro. Nada de eso. En 1976 salió a la luz lo que realmente preocupaba a Garfield, porque el equipo de Winner había plasmado, aunque con un enfoque distinto al suyo, la esencia de la indefensión y del terror del individuo en una sociedad en descomposición, y la había llevado a límites insospechados.

\section{AsPectos interteXtuales}

Un paralelismo evidente es el binomio Heart of Darkness (1899), de Joseph Conrad, y su adaptación cinematográfica (también más ruidosa), Apocalypse Now (1979). Cuando apartamos el velo, descubrimos que ambos binomios no están tan alejados como pudiera parecer. En la novela, el capitán Marlow se adentra en primera persona en un viaje abrumador, no solo físico y psicológico, sino también moral, al interior del Estado Libre del Congo (una gran ironía, lo de libre), controlado directamente por Leopoldo II de Bélgica (y no por el gobierno belga). Y este estado libre no es otro que el interior de cada persona, y por eso este opresivo viaje puede desarrollarse en la guerra de Vietnam, en una cárcel o en el espacio exterior, da igual, porque el fondo permanece inalterado. Marlow no va allí para matar a nadie (sí, en cambio, Benjamin L. Willard en Apocalypse Now), sino para recoger el marfil que se extrae de la explotación de la cual Kurtz es propietario. El viaje al interior de la selva es paralelo al viaje interior. Y la parte humana (dentro de la deshumanización) es la de ganar 


\section{Brian Garfield: la violencia como única solución}

terreno, con un Marlow yendo al «más remoto paraje navegable» (Conrad, 1998: 12), viendo por el camino lo que la civilización estaba haciendo en el Congo y encontrando a un Kurtz moribundo («jamás había visto nada parecido a la transformación que sufrieron sus facciones [...]. Fue como si se hubiera rasgado un velo [...], gritó dos veces [...] - ¡El horror! ¡El horror!») (Conrad, 1998: 133). Marlow, sin embargo, tenía una imagen propia de Kurtz: «lo había tomado por un pintor que escribía en los periódicos, o por un periodista que sabía pintar, pero ni siquiera su primo [...] pudo decirme exactamente qué había sido» (Conrad, 1998: 138). Y si fuera político, «habría sido un espléndido líder de un partido extremista», le confesó el primo de Kurtz, «¿De qué partido?», «De cualquiera contestó el otro» (Conrad, 1998: 139).

Apocalypse Now toma un camino igualmente válido para mostrar el mismo horror. Y lo hace en la guerra de Vietnam, con más disparos, explosiones y violencia que el libro original (tal como lo hizo Death Wish). El equipo de Coppola supo transmitir esta inmersión en el horror de Marlow/Willard (quien, casualmente, se llama Benjamin). ¿Podía no hacerlo? Un empleado descontento de la empresa de Coppola filtró a la prensa una nota interna que el director había escrito (Coppola, 1977, s. pág.), en la que se puede ver a un Coppola «sincero y duro, paranoico» (Galvin, 2009, s. pág.). La ficción se confunde con la realidad.

Hay otro aspecto importante de la película Death Wish: muestra aquello que importa al poder y lo que es capaz de hacer para conservarlo. Cuando bajan las estadísticas de criminalidad, los políticos y la policía no quieren detener al vigilante, no quieren matarlo (no desean un "mártir"). Solo se les ocurre asustarlo, y para hacerlo recurren al encubrimiento, escondiendo pruebas, y a la mentira continuada, esperando que Paul se vaya a otra ciudad. En la novela original, los policías son inútiles a la hora de resolver cualquier caso, pero no por inutilidad individual, sino porque deben seguir unas normas, unas leyes, que ya no funcionan.

Existe otro punto de vista diferente entre el libro y la película, en Death Wish: el final. El final de la novela es cortante, aterrador, y no parece tan abierto como cabría suponer en una primera lectura: nos muestra la complicidad de la policía (personificada en una sola figura, en un solo policía) porque, en el fondo, lo que hace el vigilante le viene muy bien. La policía ya está involucrada (probablemente desde las primeras muertes), pero no en el sentido que tocaría legalmente. En el film, en cambio, la situación malsana de la policía se muestra continuamente (ya no hace falta remarcarla en un final como el de la novela) y es Paul quien ha de trasladarse a Chicago obligado por el chantaje policial, pero dispuesto a continuar el trabajo de vigilante, con el famoso gesto de los dedos en forma de pistola apuntando a unos malhechores que molestan a una chica. 
Hay que hacer hincapié en otro de los puntos fuertes de la novela: la crítica mordaz del sistema jurídico-político estadounidense, en boca de los personajes (siempre anónimos aunque tengan nombres) o, incluso, del propio narrador, capaz de introducir nombres propios de famosos o de dar suficientes pistas de los «culpables» de la situación o de los que «facilitan» una oportunidad. Así, cuando Paul va a Tucson (Arizona) por trabajo, el narrador dispara cosas como que

aquí todos eran absolutamente de derechas, era el país de Goldwater [...]. Veían comunistas detrás de cada matorral y querían lanzar bombas sobre Moscú y Pekín. Tenías derecho a un buen transporte si podías comprarte un Cadillac; Tucson no tenía un trasporte público que valiese la pena mencionar (Garfield, 1991: 84).

También una mujer que se encuentra en un bar dispara a matar diciendo: «El odio es un sentimiento muy estimulante, ¿no lo sabía? [...] estaba sentada en la barra pensando en la forma de matar al malnacido de mi marido» (Garfield, 1991: 92); y, cuando Paul le pregunta si tiene hijos, ella responde: «No estoy preparada para criar a mis hijos, lo ha dicho el juez [...]. Todo ayuda cuando tu marido es abogado y el juez es amigo suyo» (Garfield, 1991: 93). Y, otra vez, el narrador:

Times Square era como una úlcera, los cuerpos de los rateros dando empujones, turistas boquiabiertos, hombres prostituidos haciéndose el gallito [...] Parejas de policías cada pocos metros: todos sobornados, o, si no, la mitad de la gente que corría por allí debería haber sido arrestada (Garfield, 1991: 109).

Son algunos ejemplos de un constante goteo que, a lo gota china, acaba provocando al lector un efecto psicológico de terrible empatía con los personajes que padecen cotidianamente los abusos del sistema, no tanto individual, sino colectivo, como una conspiración. Y, como lector, es realmente fácil cambiar la imagen de los personajes por personas reales, anónimas, que sufren; o, incluso, por gente próxima (conocidos, amigos, familiares) que padecen o han tenido que soportar y tragar. Garfield consigue este efecto de una forma visual y con un estilo llano, directo y muy efectivo. Winner lo tuvo fácil al fotografiarlo. El acierto del film reside en que es capaz de destilar ese fuerte brebaje y concentrar todo su hedor en esa gota que va cayendo al espectador, que sufre como sufren los personajes y que solo necesita de un gesto, de una inmundicia visual, de una mueca perforante, para sentir la injusticia en su piel. 
Brian Garfield: la violencia como única solución

\section{LA ESTELA DE LA ADAPTACIÓN}

Garfield reniega tanto del resultado del film de Winner-Bronson que escribe una secuela, Death Sentence (1975). La primera parte del libro sigue la línea de Death Wish, pero, a partir de cierto nivel, da un giro, demasiado forzado, como si el autor planease censurarse a sí mismo, subsanar errores. Parece como si Garfield traicionara el espíritu de su propio personaje. La pregunta clave es: si la película no se hubiera estrenado nunca, ¿hubiera escrito una segunda parte? Si la respuesta es no (como se desprende de las declaraciones del propio autor [Tranter, 2008: s. pág.]), conviene señalar que suele ser una mala práctica, para un escritor, hacer lo que hizo Garfield. Y la prueba la tenemos no tanto en las secuelas fílmicas como en la adaptación de Death Sentence del 2007, en la que se vuelve a adoptar el trasfondo de la historia, de la psicología tan llana, tan real, de Paul (ahora Nick), con resultados todavía más directos y brutales que en cualquiera de sus dos novelas. Además, en este caso también encontramos el espíritu de la historia inicial, pero con la parte de brutalidad de las anteriores películas de Winner (y no solo en la parte final, como alega Garfield [Tranter, 2008: s. pág.]). No deja de ser curioso que el escritor defienda esta adaptación cinematográfica (exceptuando su último tercio) del director, James Wan, alegando que «estaba muy bien dirigida», o que «teniendo en cuenta el presupuesto limitado [...] pensé que había hecho un excelente trabajo al establecer la situación y su entorno, y al mostrarnos los personajes desarrollados en el buen guion de Jeffers» (Tranter, 2008: s. pág.). La respuesta quizás la encontramos en el hecho de que, a diferencia de las secuelas anteriores, en este proyecto sí estaba implicado Garfield, aunque terminaron rechazando el guion que él mismo había escrito para ofrecerle su redacción a Ian Mackenzie Jeffers (Tranter, 2008: s. pág.).

Las secuelas fílmicas de Death Wish carecen de la huella de Garfield, pero hay que hacer una pequeña parada en Death Wish II (1982), también dirigida por Michael Winner, para enriquecer las aportaciones del lenguaje fílmico a la historia. En apariencia, podría tratarse de una secuela sin trascendencia, de las que tanto abundan en las pantallas (tan en boga actualmente), pero, al leer algunos comentarios sobre la película, un análisis detallado aflora algo oculto y realmente impactante. Así, Roger Ebert, en su crítica de Death Wish II, se vio obligado a dar «una palabra de explicación» (Ebert, 1982: s. pág.) de por qué adjudicó una valoración “sin estrellas" a la película (cuando la menor puntuación que otorgaba normalmente era de media estrella) y puesto que solo daba esta valoración a películas «artísticamente ineptas y moralmente repugnantes» (Ebert, 1982: s. pág.). ¿Qué es lo que le pareció tan repugnante? Resulta que en toda su crítica no lo menciona. Solo habla de «una serie de asesinatos tontos» (Ebert, 1982: s. pág.) y el hecho de no analizar en profundidad qué le hizo adoptar tales calificativos resulta tan inquietante como la propia 
película. Tenemos una pista en uno de los aspectos más notables de la novela de Garfield Death Wish: interiorizar el horror insoportable que sufren personas anónimas cada día. El equipo de Death Wish II asimiló esa esencia de la novela original y la personificó (otra vez) en la hija de Paul, Carol, aunque a un ritmo mayor y sin dilaciones. Después de ser violada en la trama de la primera película y quedar en estado catatónico, se retoma la historia inmediatamente después, aunque pasados ocho años en tiempo real para los espectadores de los estrenos de ambas películas, con Carol internada en un hospital psiquiátrico (otro hecho inquietante: las dos perspectivas del tiempo funcionan a la vez y son aplicables al mismo tiempo en Death Wish II, donde pueden haber pasado dos días u ocho años). Carol va mejorando y, aunque no ha recuperado el habla, comprende lo que le dicen Paul y su nueva pareja (Geri), les acompaña en sus paseos (donde visitan mercadillos y toman helados) y se hace entender con la mirada y gestos aparentemente normales. Hay esperanza... pero dura poco. De repente, la secuestran y la violan por segunda vez. Es en esta escena donde la película se sale del marco otorgado a las secuelas sin interés. ¿Cómo alguien puede resistir una segunda violación cuando todavía se está recuperando de la primera? Es inevitable pensarlo mientras se visiona la película. Y la actitud del personaje de Carol es abrumadora: acepta la violación sin reaccionar, ante la atónita mirada del violador, que la acaricia e incluso le habla para intentar convencerla de lo que va a hacer. Esta escena es tan terriblemente actual, casi cuarenta años después, que entristece y enfurece a partes iguales.

El impacto de Death Wish se muestra en muchos niveles sociales, desde la literatura hasta los videojuegos, pasando por la música, la televisión y, cómo no, la política. Pero el verdadero peso de la historia se encuentra en la consciencia personal y social del mundo en el que vivimos. En un mundo donde los índices de criminalidad no hacen más que aumentar, o para referir una realidad más próxima- en un país civilizado donde las grandes ciudades hierven de indefensión, de impotencia, de desconcierto, el personaje de Paul Benjamin no puede ser más actual. Y es que, ¿cuánto horror puede soportar una persona, mantenerse sin hacer nada y no enloquecer?

\section{Bibliografía CITADA}

CONRAD, Joseph (1998), En el cor de les tenebres, ed. de M Vancells i Flotats, Barcelona, Edicions 62.

Coppola, Francis (1977), «Case Histories of Business Management: Hollywood Artistic Division. A memo from Francis Coppola. Incl. A Memorandum», Esquire, págs. 190-196 [En línea: 


\section{Brian Garfield: la violencia como única solución}

https: / / classic.esquire.com/article/1977/11/1/ case-histories-ofbusiness-management-hollywood-artistic-division. Fecha de consulta: $13 / 10 / 2019]$.

D’Ambrosio, Brian (2011), Menacing Face Worth Millions: Life of Charles Bronson, Montana, Jabberwocky Press.

DAvidson, Bill (1974), «The American Discovery Of Charles Bronson», The Ledger, pág. $7 \mathrm{~d}$. [En línea: https: / / news. google.com/newspapers?nid=1346\&dat=19740922\&i $\mathrm{d}=$ KgswAAAAIBAJ\&sjid=5_oDAAAAIBAJ\&pg $=6504,6343869 \& \mathrm{hl}=$ en. Fecha de consulta: 10/10/2019].

EberT, Roger (1982), «Death Wish II», Chicago Sun-Times, 01/01 [En línea: https://www.rogerebert.com/reviews/death-wish-ii-1982. Fecha de consulta: 23/02/2020].

Flory, Dan (2008), Philosophy, Black Film, Film Noir, Pennsylvania, The Pennsylvania State University Press.

Galvin, Peter (2009), «Apocalypse Then», SBS Film, s. pág. [En línea: https://www.sbs.com.au/movies/article/2009/05/14/apocalypsethen. Fecha de consulta: 13/10/2019].

Garfield, Brian (1991), Death Wish, ed. de M. de Pedrolo, Barcelona, Edicions 62.

Mandeville-Gamble, Steven (1997), "Guide to the Black Lizard Press Archive, 1977-1994», The Online Archive of California (OAC), M0932, págs. 2-3 [En línea: http://pdf.oac.cdlib.org/pdf/stanford/mss/m0932.pdf. Fecha de consulta: 5/10/2019].

MiLl, John Stuart (1867), Inaugural Address. Delivered to the University of St. Andrews, Londres, Longmans.

Talbot, Paul (2006), Bronson's Loose! The Making of the Death Wish Films, Lincoln, iUniverse.

Tranter, Nikki (2008), «Historian: Interview with Brian Garfield», PopMatters, s. p. [En línea: https://www.popmatters.com/historianinterview-with-brian-garfield-2496171202.html. Fecha de consulta: 5/10/2019].

Fecha de recepción: 01/03/2020.

Fecha de aceptación: 10/06/2020. 